Gilles Lacroix MD, Martin R. Lessard MD FRCPC, Claude A. Trépanier MD FRCPC

\title{
Treatment of post- operative nausea and vomiting: comparison of propofol, droperidol and metoclopramide
}

Conclusion: A subhypnotic dose of propofol (10 $\mathrm{mg}$ iv) is less effective than the conventional antiemetic drugs droperidol and metoclopramide for the treatment of PONV in the PACU.

Purpose: To compare the efficacy of propofol in a subhypnotic dose (10 mg iv), droperidol (1.25 mg iv), or metoclopramide (10 $\mathrm{mg} \mathrm{iv}$ ) in the treatment of PONV in the post anaesthesia care unit (PACU).

Methods: In a prospective, randomized, double-blind protocol, over four months, all eligible inpatients and outpatients were asked to give their consent to be included in the study should they suffer PONV in the PACU. They received a standardized general anaesthetic without any prophylactic antiemetic drug. In the recovery room, patients complaining of persistent nausea (lasting more than ten minutes) andlor experiencing at least two episodes of retching or vomiting were given one of the three study drugs. Recurrence of retching or vomiting was recorded for $60 \mathrm{~min}$ after administration of the study drug and nausea severity was assessed on a visual analog scale. Patients still complaining of PONV $30 \mathrm{~min}$ after administration of the study drug received a rescue medication (dimenhydrinate).

Results: Seventy-eight patients received one of the study drugs. The recurrence of retching or vomiting was higher with propofol (58\%) than with droperidol (4\%) or metoclopramide (24\%) $(P<0.001)$. More patients who received propofol needed the rescue medication (54\%) than those who received droperidol $(15 \%)$ or metoclopramide $(28 \%)(P<0.02)$. No difference was observed in nausea severity.

\section{Key words}

ANAESTHETICS, INTRAVENOUS: propofol; ANTIEMETIC: propofol; droperidol; metoclopramide; COMPLICATIONS, POSTOPERATIVE: nausea; vomiting.

From the Department of Anaesthesia, Hôpital de l'EnfantJésus, Laval University, Québec, Canada.

Presented, in part, at the annual meeting of the Canadian Anaesthetists' Society, Edmonton, Canada, June 1994.

Address correspondence to: Dr. Martin Lessard, Département d'anesthésie-réanimation, Hôpital de l'Enfant-Jésus,

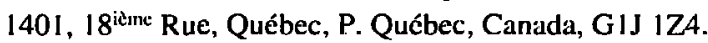

Phone: (418) 649-5807. Fax: (418) 649-5918.

Accepted for publication 19th October, 1995.
Objectif: Comparer le propofol à dose subhypnotique $(10 \mathrm{mg}$ iv), le dropéridol (1,25 mg iv) et le métoclopramide (10 mg iv) pour le traitement des nausées et vomissements postopératoires (NVP) à la salle de réveil.

Méthode: Pendant quatre mois, tous les patients éligibles ont été solicités et ont consenti à parificiper à une étude prospective, randomisée et en double aveugle dans l'éventualité de NVP à la salle de réveil. L'anesthésie était standardisée et ne comportait pas d'antiémétiques. A la salle de réveil, les patients qui se plaignaient de nausées persistantes (dix min et plus) et/ou qui éprouvaient au moins deux épisodes d'efforts de vomissements ou des vomissements ont reçu un des trois médicaments. La récidive des efforts de vomissements ou des vomissements a été notée pendant 60 min après l'administration du médicament à l'étude et l'importance de la nausée a été évaluée sur une échelle visuelle analogue. Les patients qui continuaient de se plaindre de NVP 30 min après l'administration d'un des médicanents étudiés ont reçu un médicament de sauvetage (dimenhydrinate).

Résultats: Soixante-dix-huit patients ont reçu un des médicaments étudiés. La récidive d'efforts de vomissements et de vomissements a été plus élevée avec le propofol (58\%) qu'avec le dropéridol (4\%) et le métoclopramide $(24 \%)(P<$ $0.001)$. Les patients ayant reçu le propofol ont été plus nombreux (54\%) à recevoir le médicament de sauvetage que ceux qui avaient reçu le dropéridol (15\%) ou le métoclopramide $(28 \%)(P<0,02)$. La gravité de la nausée pas été différente entre les groupes.

Conclusion: La dose subhypnotique de propofol (10 mg iv) est moins efficace que les antiémétiques habituels dropéridol et métoclopramide pour traiter les NVP à la salle de réveil.

Nausea, retching and vomiting are the most frequent complications occurring in the post anaesthesia care unit (PACU). ${ }^{1}$ In outpatient surgery, they are important 
causes of delay in discharge and unplanned hospital admission. ${ }^{2}$ In adults, in the absence of prophylactic antiemetic drugs, the incidence of PONV after general anaesthesia has not showed improvement in recent years and is still around $10 \%$ in the PACU, ${ }^{1.3}$ increasing to 20 to $40 \%$ when the follow up extends beyond the PACU period. ${ }^{4-6}$ When patients are asked about problems associated with previous anaesthesia, nausea and vomiting is by far the most frequent complication mentioned and the most distressing adverse effect they will remember from anaesthesia. ${ }^{4.7}$ Many antiemetic drugs have been studied in order to reduce the incidence and severity of this complication. Antiemetic drugs can be administered prophylactically to every patient undergoing general anaesthesia, but many anaesthetists prefer to treat only those who suffer PONV in the PACU. However conventional antiemetic drugs have variable efficacy and are associated with side effects such as sedation, extrapyramidal symptoms, dysphoria, confusion, or hypotension. ${ }^{4}$ In a recent study, Borgeat $e t$ al. reported that propofol in subhypnotic doses was superior to placebo for the treatment of PONV. ${ }^{8}$ Interestingly, this was associated with very few side effects and was not different from placebo. However, no study has compared the efficacy of propofol with conventional antiemetic drugs. Therefore, this prospective, randomized, double-blind study was designed to compare the efficacy of propofol in a subhypnotic dose, with droperidol and metoclopramide in the treatment of PONV.

\section{Methods}

\section{Patients}

The protocol was approved by the Hospital Ethics Committee. Over four months, informed consent was obtained from all patients considered eligible for the study. Inclusion criteria were: patients aged between 18 and $70 \mathrm{yr}$, ASA physical status 1-3, scheduled for an elective surgical procedure under general anaesthesia. Exclusion criteria were: pregnancy, intake of any antiemetic drug within $24 \mathrm{hr}$ of surgery, history of allergy to one of the study medications, morbid obesity; and anticipated requirement of a nasogastric tube in the postoperative period (e.g., major abdominal surgery). Eight-hundred and fifty-nine (859) patients gave their consent to be enrolled in the study should they suffer from PONV in the PACU. All these patients received a standardized general anaesthesia. Inpatients received sublingual lorazepam $1 \mathrm{mg}$ as premedication while outpatients were not given any premedication. Anaesthesia was induced with fentanyl $\left(1-3 \mu \mathrm{g} \cdot \mathrm{kg}^{-1}\right)$, sufentanil $\left(0.1-0.3 \mu \mathrm{g} \cdot \mathrm{kg}^{-1}\right)$, or alfentanil $\left(10-15 \mu \mathrm{g} \cdot \mathrm{kg}^{-1}\right)$ and thiopentone $\left(3-6 \mathrm{mg} \cdot \mathrm{kg}^{-1}\right)$ iv and a neuromuscular blocking agent was given to facilitate tracheal intubation. Anaesthesia was maintained with fentanyl up to 8 $\mu \mathrm{g} \cdot \mathrm{kg}{ }^{-1}$, sufentanil up to $1.0 \mu \mathrm{g} \cdot \mathrm{kg}^{-1}$, or alfentanil up to $50 \mu \mathrm{g} \cdot \mathrm{kg}^{-1}$, isoflurane $\left(0.2-1.0 \%\right.$ end-tidal) in a $\mathrm{N}_{2} \mathrm{O}-\mathrm{O}_{2}$ mixture, and a neuromuscular blocking agent was used when required. At the end of surgery, neuromuscular blockade was antagonized with neostigmine $40 \mu \mathrm{g} \cdot \mathrm{kg}^{-1}$ and glycopyrrolate $10 \mu \mathrm{g} \cdot \mathrm{kg}^{-1}$ if neuromuscular function, monitored by train of four stimulation, had not completely recovered. No patient received propofol, droperidol, metoclopramide, or any other antiemetic drug as part of the anaesthetic technique. In the PACU, pain was treated with an opioid (fentanyl 50-100 $\mu \mathrm{g} i \mathrm{v}$ ) or patient controlled analgesia with morphine.

\section{Protocol}

In the PACU, patients complaining of nausea lasting at least ten minutes or experiencing at least two episodes of retching or vomiting were enrolled in the study. ${ }^{9}$ According to a computer generated randomisation table, they received one of the three study drugs; propofol 10 $\mathrm{mg}$, droperidol $1.25 \mathrm{mg}$ or metoclopramide $10 \mathrm{mg} i \mathrm{v}$. Patients were not included if an endotracheal tube or a nasogastric rube was in place at the time of emesis. The three drugs were prepared by the pharmacy department. They were mixed with $5 \mathrm{ml}$ Intralipid ${ }^{\circledR}$ to make them undistinguishable. The drugs were injected over one minute. Patients were then observed in the PACU for $\geq 60$ min. Thirty minutes after administration of the study drug, patients who were still complaining of nausea or vomiting were given dimenhydrinate $50-100 \mathrm{mg}$ $i v$ as a rescue medication.

\section{Measurements}

Decrease in severity of nausea, or absence of recurrence of retching or vomiting can be related to either the effect of the drug or the natural history of PONV. Thus the major endpoint was the incidence of treatment failure defined as recurrence of retching or vomiting during the $60 \mathrm{~min}$ after the administration of the study drug. Improvement in nausea severity was the second endpoint and was assessed on a visual analog scale (VAS) where 0 represents the absence of nausea and 10 the most severe nausea. ${ }^{9,10}$ Measurements were done just before the injection of the study drug (time 0 ) and 5,10 , $15,20,30,45$ and $60 \mathrm{~min}$ after injection. At the same time, sedation was evaluated on a four point scale slightly modified from Borgeat et al. (Table I). ${ }^{8}$ The incidence of the following side effects was also recorded: pain on injection, confusion, dysphoria, extrapyramidal symptoms, and hypotension (systolic blood pressure $<90 \mathrm{mmHg}$ ). All data were collected by a research assistant nurse or one of the authors. After departure 
from the PACU, the incidence of postoperative nausea and vomiting was recorded by the ward nurse, until midnight for inpatients, and until leaving the day surgery unit for outpatients.

\section{Statistical analysis}

Data are reported as mean \pm SD. Continuous parametric variables were analyzed with analysis of variance (ANOVA) followed by Tukey's test, and nonparametric variables with the Chi-square test with Bonferroni's correction. Severity of nausea on the VAS was analyzed as change in nausea severity score. Thereby a negative VAS score indicates a decrease in nausea severity. The three groups were compared using multivariate analysis of variance (MANOVA). Sedation on the sedation rating scale was analyzed with the Kruskall-Wallis test. A $P<0.05$ was considered significant. The $95 \%$ confidence intervals were calculated for recurrence of retching or vomiting.

\section{Results}

Of the 859 patients who consented to the study, 78 (9.1\%) suffered postoperative emesis meeting the inclusion criteria in the PACU and were enrolled in the study. There was no difference between the three groups with respect to age, weight, sex, period of menstrual cycle, ratio of inpatients/outpatients, ASA physical status, history of emesis following a previous anaesthesia, or history of motion sickness (Table II). The three groups were comparable for type of surgery, duration of anaesthesia, anaesthetic agents received, reversal of neuromuscular blockade, use of a gastric tube intraoperatively (Table III). Percentages of patients requiring an analgesic in the PACU were also not different. No patient experienced pain on injection of the study drugs.

The incidence of retching or vomiting recurring after the administration of the study drug is presented in Figure 1. Recurrence of retching or vomiting was more frequent in the group who had received propofol than in the groups who had received droperidol or metoclopramide $(P<0.001)$. Likewise more patients in the propofol group needed dimenhydrinate as a rescue medication than in the droperidol or metoclopramide groups $(P<0.01)$. The efficacy of the three drugs in the treatment of nausea is presented in Figure 2. Just before injection (time 0), the severity of nausea on the VAS was comparable among the three groups. After administration of the study drug, the severity of nausea decreased in the three groups without difference among them. Thirty and sixty minutes after the administration of the study drug, patients who had received droperidol were more sedated than those who had received metoclopramide or propofol $(P<0.02)$. One patient who had
TABLE I Sedation rating scale

1 Paticnt fully awakc

2 Patient awakening to normal voice

3 Patient awakening only to loud voice

4 Patient awakening only to tactile stimulus

Modified from Borgeat A. et al. ${ }^{8}$

TABLE II Patient demographic characteristics

\begin{tabular}{llll}
\hline & $\begin{array}{l}\text { Metoclo- } \\
\text { pramide }\end{array}$ & Droperidol & Propofol \\
\hline Number of patients & 25 & 27 & 26 \\
Age (yr) & $46.5 \pm 14$ & $42.7 \pm 14$ & $43.3 \pm 11$ \\
Weight (kg) & $64.4 \pm 11$ & $67.8 \pm 10$ & $67.5 \pm 14$ \\
Sex m/f (n) & $3 / 22$ & $4 / 2.3$ & $4 / 22$ \\
Menstrual cycle 1-8 d (\%) & 12 & 7 & 23 \\
Ratio of inpatients (\%) & 68 & 85 & 69 \\
ASA physical status 1/2/3 & $15 / 10 / 0$ & $19 / 6 / 2 /$ & $17 / 8 / 1$ \\
History of PONV (\%) & 63 & 47 & 48 \\
History of motion sickness (\%) & 24 & 19 & 15 \\
\hline
\end{tabular}

Data are mean $\pm \mathrm{SD}$, or ratio (\%); $n=$ number of patients; $P=\mathrm{NS}$ between the three groups for all variables.

TABLE III Anaesthetic and surgical data

\begin{tabular}{llll}
\hline & $\begin{array}{c}\text { Metoclo- } \\
\text { pramide }\end{array}$ & Droperidol & Propofol \\
\hline Number of patients & 25 & 27 & 26 \\
Type of surgery (\%) & & & \\
- Orthopaedics & 20 & 19 & 27 \\
- Eyc \& ENT & 8 & 4 & 8 \\
- Gencral & 16 & 33 & 31 \\
- Gynaecological & 24 & 33 & 27 \\
- Vascular & 16 & 7 & 4 \\
- Other & 16 & 4 & 4 \\
Duration of anaesthesia (min) & $114 \pm 75$ & $116 \pm 57$ & $102 \pm 70$ \\
Dose of opioids ( $\left.\mu \mathrm{g} \cdot \mathrm{kgg}^{-1}\right)$ & & & \\
- Fentanyl $(n=30)$ & $3.2 \pm 2.0$ & $3.2 \pm 1.0$ & $2.7 \pm 1.0$ \\
- Sufentanil $(n=44)$ & $0.6 \pm 0.4$ & $0.5 \pm 0.3$ & $0.4 \pm 0.1$ \\
- Alfentanil $(n=4)$ & $44 \pm 3$ & $29 \pm 0$ & $30 \pm 0$ \\
Neuromuscular blockade & & & \\
$\quad$ reversal (\%) & 60 & 52 & 62 \\
Intraoperative gastric tube $(\%)$ & 68 & 85 & 77 \\
Analgesics in PACU $(\%)$ & 60 & 74 & 73 \\
\hline
\end{tabular}

Data are mean $\pm \mathrm{SD}$, or ratio $(\%) ; n=$ number of patients; $P=\mathrm{NS}$ between the three groups for all variables.

received droperidol presented symptoms of extrapyramidal rigidity in the PACU within one hour of drug administration. After. departure from the PACU (until midnight for inpatients and until leaving the day surgery unit for outpatients), the incidence of nausea or vomiting (metoclopramide $60 \%$, droperidol $56 \%$, propofol $65 \%$ ) and the use of antiemetic drugs (metoclopramide 


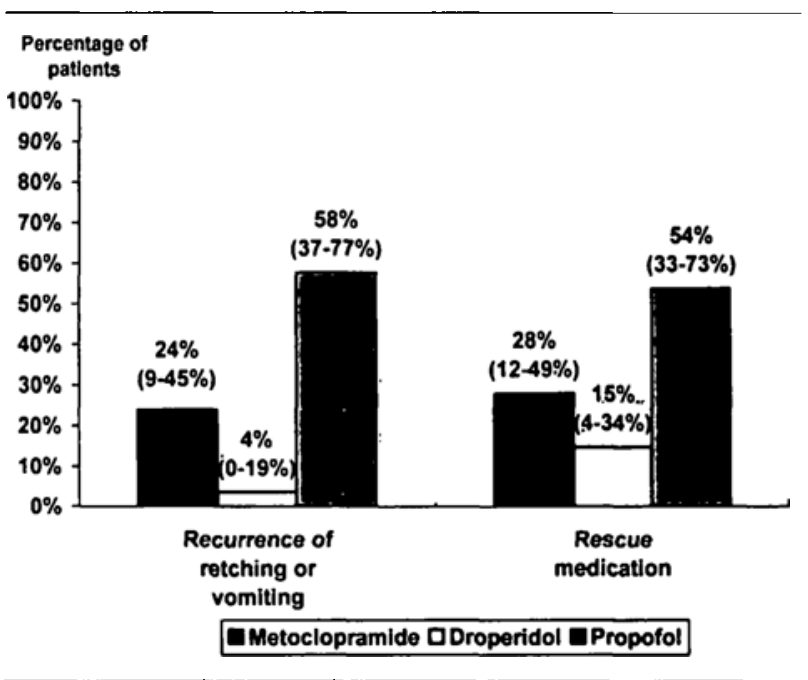

FIGURE I Recurrence of retching or vomiting for the three antiemetic drugs, and need for rescue medication (Percentage: $95 \%$ confidence intervals in parenthesis; $P<0.001$ and $P<0.01$ respectively, propofol vs droperidol and metoclopramide; $\chi^{2}$ test).

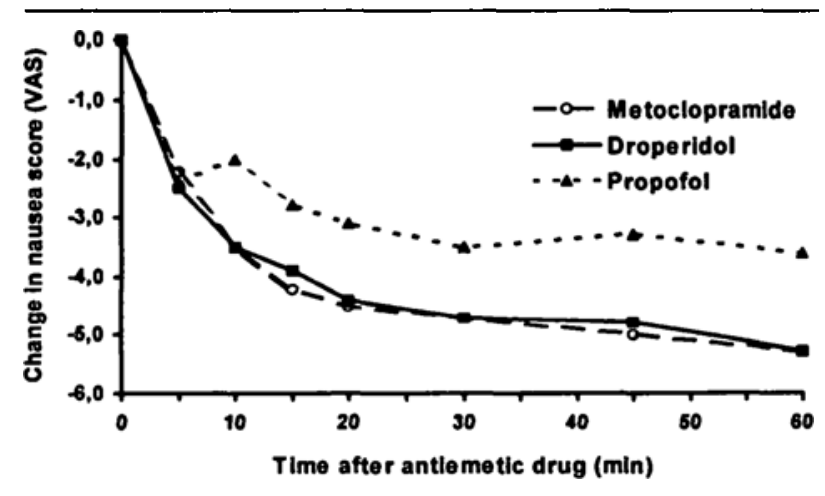

FIGURE 2 Change in severity of nausea on the VAS $(P=0.07$; MANOVA). Severity of nausea at the time of injection of the study drug (time 0 ) was not different between the three groups, and it has been normalized to 0 on the VAS. Thus change in VAS score indicate change in nausea sevcrity (a negative value indicating a decrease in severity).

$32 \%$, droperidol $33 \%$, propofol $50 \%$ ) were comparable for the three groups.

\section{Discussion}

In this prospective randomized double-blind study, the efficacy of propofol in a subhypnotic dose $(10 \mathrm{mg} i \mathrm{v})$, droperidol (1.25 mg $i v)$, or metoclopramide (10 mg iv) were compared in the treatment of PONV in the PACU. Although no difference among the three drugs was observed in nausea severity assessed on the VAS, the recurrence of retching or vomiting (the major end point of this study) was higher with propofol ( $58 \%$ ) than with droperidol $(4 \%)$ or metoclopramide $(24 \%)$, and more patients who received propofol needed the rescue medication than those who received droperidol or metoclopramide. After leaving the PACU the recurrence of emesis was not different among the three groups and was comparable to the incidence observed by Cohen $e t$ $a l .{ }^{6}$ This suggests that late recurrence of PONV is not modified by the administration in the PACU of any of the three antiemetic drugs studied.

Compared with other general anaesthetic techniques, propofol anaesthesia is associated with a lower incidence of PONV in adults and children. ${ }^{11,12}$ Some authors have suggested that propofol has a direct antiemetic effect. ${ }^{13.14}$ Borgeat et al. have recently reported the efficacy of subhypnotic doses of propofol compared with placebo for the treatment of PONV in the PACU. ${ }^{8}$ Sixty-nine percent of patients were treated successfully with $10 \mathrm{mg}$ propolol $(81 \%$ when a second dose was administered) compared with $35 \%$ treated with placebo. Interestingly, the incidence of side effects with propofol was not different from that with placebo. However, the efficacy of propofol has not been compared with that of conventional antiemetic drugs.

The physiology of PONV is complex and multifactorial. ${ }^{4.15}$ The vomiting centre may be stimulated by direct afferents from the gastrointestinal tract, the pharynx, the vestibular system, the cortical structures, or by the chemoreceptor trigger zone (CTZ) located in the area postrema. Four neurotransmitter systems appear to be involved in mediating nausea and vomiting through the CTZ: the dopaminergic, muscarinic cholinergic, histaminergic and scrotoninergic systems. In addition the CTZ is rich in opioid receptors. Conventional antiemetic drugs used to treat PONV operate through these receptors. Droperidol and metoclopramide act by blocking dopaminergic receptors. Metoclopramide also has direct peripheral effects on the gastrointestinal tract. The mechanisms of the antiemetic effects of a subhypnotic dose of propofol are not known. With such a low dose, it is unlikely that it could be explained by its sedating effects. It has been suggested that propofol would exert its antiemetic action by modulating subcortical pathways, although this has not been well substantiated. ${ }^{16}$ Some clinical side effects of propofol (e.g., spontaneous movements, oculogyric crisis) also suggest that it might act as a dopaminergic antagonist, ${ }^{17}$ but a recent study did not support that hypothesis. ${ }^{18}$ Propofol has no known antiserotoninergic or anticholinergic activity either.

Risk factors associated with an increased incidence of PONV include younger age, female sex especially during menses, obesity, history of PONV following a previous anaesthesia, history of motion sickness, type of surgical procedure, longer duration of anaesthesia, 
anaesthetic technique, use of opioids, reversal of neuromuscular blockade, and postoperative pain or hypotension. ${ }^{4,6.15}$ Preoperative medication such as lorazepam may reduce the incidence or severity of PONV. ${ }^{19}$ These factors should be controlled for in clinical trials on PONV. ${ }^{10}$ In this study their prevalence was comparable among the three groups. Only $9.1 \%$ of the patients who gave consent suffered from PONV in the PACU and were finally included in the protocol. This is similar to the incidences reported by Hines et $a l^{1}{ }^{1}$ and by us in a previous study. ${ }^{3}$ This rather low incidence is explained by the tight inclusion and exclusion criteria used and by the fact that patients had to complain spontaneously of nausea. The objective was to study PONV that was severe enough to require treatment and to avoid treating PONV that would spontancously subside. A higher incidence of PONV can also be observed when patients are systematically asked about it and when the observation period is extended beyond the PACU. ${ }^{3.6}$ To ensure blinding, the three drugs studied were prepared with 5 $\mathrm{ml}$ Intralipid ${ }^{\circledR}$ which does not possess antiemetic properties. ${ }^{20}$ No patient complained of pain on injection, suggesting that the blinding protocol was successful.

Although a statistically and clinically significant difference between propofol and the two other drugs was found in the recurrence of retching or vomiting, no difference was observed in nausea severity during the 60 min observation period. An inadequate number of patients may explain a failure to detect a real difference (type II error) with a measuring tool that is not very sensitive, such as the VAS. Besides, $30 \mathrm{~min}$ after the administration of the study drug, patients with persistent nausea or vomiting were allowed to receive dimenhydrinate. Therefore, during the last $30 \mathrm{~min}$ of observation, measurements of nausea severity were altered by the effect of dimenhydrinate, which was given to a higher number of patients in the propofol group than in the two other groups.

The higher incidence of treatment failure in the propofol group might be explained by the pharmacokinetic characteristics of propofol (short distribution and elimination half-lives). ${ }^{21}$ The dose of $10 \mathrm{mg}$ propofol corresponds to 110 to $220 \mu \mathrm{g} \cdot \mathrm{kg}^{-1}$ for patients weighing 45 to $90 \mathrm{~kg}$ respectively. Although no correlation was found between the dose per kilogram and failure rate, the efficacy of propofol might have been improved by the administration of a second dose or an infusion. ${ }^{8}$ This type of regimen has been used successfully for the treatment of chemotherapy induced nausea and vomiting. ${ }^{22}$ However, the use of multiple doses or infusion of a short acting drug is not a very useful regimen in the PACU.

This study confirmed the low incidence of sedation with low dose propofol as already reported ${ }^{8}$ Droperidol, although an effective antiemetic drug, was associated with more sedation than metoclopramide and propofol. Here, again, the use of dimenhydrinate may have affected the sedation score at $60 \mathrm{~min}$, but not significantly, since the droperidol group received less dimenhydrinate and was still the most sedated group. This sedative effect of droperidol might delay discharge from the PACU. Droperidol can also produce extrapyramidal side effects (one patient in this study). ${ }^{23}$ Metoclopramide does not cause sedation and is associated with a lower incidence of extrapyramidal symptoms, which might be a considerable advantage.

In summary, in this prospective randomized doubleblind study, propofol, droperidol, and metoclopramide were compared for the treatment of PONV in the PACU. We conclude that a subhypnotic dose of propofol $(10 \mathrm{mg})$ is less effective than the conventional antiemetic drugs, droperidol and metoclopramide.

\section{Acknowledgements}

The authors thank their research assistant nurse Mrs. Diane Paquet, and Mrs. Line Godin for her help with the manuscript.

\section{References}

1 Hines $R$, Barash $P G$, Watrous $G, O^{\prime}$ Connor $T$. Complications occurring in the postanesthesia care unit: a survey. Anesth Analg 1992; 74: 503-9.

2 Gold BS, Kitz DS, Lecky JH, Neuhaus JM. Unanticipated admission to the hospital following ambulatory surgery. JAMA 1989; 262: 3008-10.

3 Trépanier $C A$, lsabel $L$. Perioperative gastric aspiration increases postoperative nausea and vomiting in outpatients. Can J Anaesth 1993; 40: 325-8.

4 Watcha $M F$, White $P F$. Postoperative nausea and vomiting. Its etiology, treatment and prevention. Anesthesiology 1992; 77: 162-84.

5 Palazzo MGA, Strunin L. Anaesthesia and emesis. I: ctiology. Can Anaesth Soc J 1984; 31: 178-87.

6 Cohen MM, Duncan PG, DeBoer DP, Tweed WA. The postoperative interview: assessing risk factors for nausea and vomiting. Anesth Analg 1994; 78: 7-16.

7 Kapur PA. The big "little problem" (Editorial). Anesth Analg 1991; 73: 243-5.

8 Borgeat A, Wilder-Smith OHG, Saiah M, Rifat K. Subhypnotic doses of propofol possess direct antiemetic properties. Anesth Analg 1992; 74: 539-41.

9 Bodner $M$, White $P F$. Antiemetic efficacy of ondansetron after outpatient laparoscopy. Anesth Analg 1991; 73 : $250-4$.

10 Kortilia $K$. The study of postoperative nausea and vomiting. Br J Anaesth 1992; 69 (suppl): 20S-23S. 
11 Doze VA, Shafer A, White PF. Propofol-nitrous oxide versus thiopental-isoflurane-nitrous oxide for general anesthesia. Anesthesiology 1988; 69: 63-71.

12 Watcha $M F$, Simeon RM, White PF, Stevens JL. Effect of propofol on the incidence of postoperative vomiting after stabismus surgery in pediatric outpatients. Anesthesiology 1991; 75: 204-9.

13 McCollum .JSC, Milligan KR, Dundee JW. Forum. The antiemetic action of propofol. Anaesthesia 1988; 43: 239-40.

14 Reimer EJ, Montgomery CJ, Bevan JC, Merrick PM, Blackstock D, Popovic $V$. Propofol anaesthesia reduces early postoperative emesis after paediatric strabismus surgery. Can J Anaesth 1993; 40: 927-33.

15 Andrews $P L R$. Physiology of nausea and vomiting. $\mathrm{Br} \mathrm{J}$ Anaesth 1992; 69 (suppl): 2S-19S.

16 Borgeat A, Wilder-Smith OHG, Suter PM. The nonhypnotic therapeutic applications of propofol. Anesthesiology 1994; 80: 642-56.

17 DiFlorio $T$. Is propofol a dopamine antagonist? (Letter). Anesth Analg 1993; 77: 200-1.

18 Borgeat A, Bonnefoi $H$, Tramer $M$, Bischoff $P$, WilderSmith $O H G$, Rifat $K$. Does propofol possess antidopaminergic properties? Anesth Analg 1994; 78: S43.

19 Khalil SN, Berry JM, Howard G, et al. The antiemetic effect of lorazepam after outpatient strabismus surgery in children. Anesthesiology 1992; 77: 915-9.

20 Östman PL, Faure E, Glosten B, Kemen M, Robert MK, Bedwell $S$. Is the antiemetic effect of the emulsion formulation of propofol duc to the lipid emulsion? Anesth Analg 1990; 71: 536-40.

21 Sebel PS, Lowdon JD. Propofol: a new intravenous anesthelic. Anesthesiology 1989; 71: 260-77.

22 Borgeat A, Wilder-Smith O, Forni M, Suter PM. Adjuvant propofol enables better control of nausea and emesis secondary to chemotherapy for breast cancer. Can J Anaesth 1994; 41: 1117-9.

23 Melnick B, Sawyer R, Karambelkar D, Phitayakorn P, $U_{y} N T L$, Patel $R$. Delayed side effects of droperidol after ambulatory general anesthesia. Anesth Analg 1989; 69: 748-51. 